\title{
Limitations of the Transition State Variation Model. Part 8. Dual Reaction Channels for Solvolyses of 3,4-Dimethoxybenzenesulfonyl Chloride
}

\author{
In Sun Koo, Eunju Kwon, Hojune Choi,, Kiyull Yang, Jong Keun Park, \\ Jong Pal Lee, ${ }^{4}$ Ikchoon Lee, ${ }^{\S}$ and T. William Bentley, \\ Department of Chemistry Education and The Research Institute of Natural Science, Gyeongsang National University, \\ Jiniu 660-701, Korea. "E-mail: iskoo@gsmuackr \\ "Department of Chemistry, Gyeongsang National University, Jinju 660-701, Korea \\ Department of Chemistry, Dong-A University, Pusan 604-714, Korea \\ ${ }^{\$}$ Department of Chemistry, Inha University, Incheon 402-751, Korea

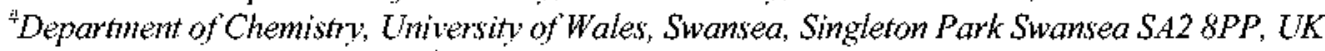 \\ "E-mail:consolvol@swansea.ac.uk \\ Received September 17, 2007
}

\begin{abstract}
Solvolyses of 3,4-dimethoxybenzenesulfonyl chloride (DSC) in water, $\mathrm{D}_{2} \mathrm{O}, \mathrm{ClI}_{3} \mathrm{OD}$, and in aqueous binary mixtures of acetone, acetonitrile, 1,4-dioxane, ethanol, methanol, and 2,2,2-trifluoroethanol (TFE) have been investigated at $25.0^{\circ} \mathrm{C}$. Kinetic solvent isotope effects (KSIE) in water and in methanol and product selectivities in alcohol-water mixtures are also reported. The Grunwald-Winstein plot of first-order rate constants for the solvolyic reaction of DSC with $Y_{C I}$ shows marked dispersions into separated lines for various aqueous mixtures. With use of the extended Grunwald-Winstein equation, the $l$ and $m$ values obtained are 1.12 and 0.58 respectively for the solvolyses of DSC. The relatively large magnitude of $l$ is consistent with substantial nucleophilic solvent assistance. From Grunwald-Winstein plots the rate data are dissected approximately into contributions from two competing reaction channels. This interpretation is supported for alcohol-water mixtures by the trends of product selectivities, which show a maximum for ethanol-water mixtures. From the KSIE of 1.45 in methanol, it is proposed that the reaction channel favored in methanolwater mixtures and in all less polar media is general-base catalysed and/or is possibly (but less likely) an addition-elimination pathway. $\Lambda$ lso, the KISE value of 1.35 for DSC in water is expected for $S_{\wedge} 2-S_{\wedge} \cdot 1$ processes, with minimal general base catalysis, and this mechanism is proposed for solvolyses in the most polar media.
\end{abstract}

Key Words : Solvolyses, Kinetic solvent isotope effect, General-base catalysis, Dual reaction channels

\section{Introduction}

Sulfonyl halides are known to be solvolyzed through a borderline mechanism' ${ }^{\prime}$ as in the solvolysis of benzyl chloride. ${ }^{2}$ There have been, however, much dispute over the mechanism as to whether it is an $\mathrm{S}_{\mathrm{N}} \cdot 2^{3}$ or an $\mathrm{S}_{\mathrm{A}} \mathrm{N}^{4}$ process, the former being preferred lately. A particularly important system which contains tetracoordinate sulfur is $\mathrm{ArSO}_{2} \mathrm{Cl}$; sulfonyl chlorides are important reagents in organic synthesis and substitution reactions of these compounds bridge inorganic and organic chemistry.

Solvent effects and linear free energy relationships in the solvolyses of sulfonyl halides, ${ }^{25}$ especially substituted benzenesulfonyl chlorides, have received much attention, ${ }^{5}$ but little work has been done on the solvent stoichiometric effect on alcohol-water mixed solvents, especially for the solvolyses of electron rich substituted aromatic sulfonyl chlorides.

Dispersion into separated lines in the correlation of the specific rates of solvolysis of substrates in various binary mixtures was documented ${ }^{6-10}$ in early treatments using the Grunwald-Winstein eq. (1). ${ }^{11-14.17}$

$$
\log \left(k / k_{\mathrm{c}}\right)=m Y+c
$$

In general, dispersion effects in unimolecular solvolysis ${ }^{15.16}$ make smaller contributions to the overal linear free energy relationship (LFER) than solvent nucleophilicity effects in bimolecular solvolysis. ${ }^{6.18}$ It was suggested that a second term which is governed by the sensitivity $l$ to solvent nucleophilicity $N$, should be added to Eq. (1) for bimolecular solvolysis. ${ }^{18}$ The resulting Eq. (2) is often referred to as the extended Grunwald-Winstein eqation. ${ }^{18}$

$$
\log \left(k / k_{0}\right)=m Y+l N+\mathfrak{c}
$$

Solvolytic reactions in alcohol-water mixtures lead to alcohol and ether products from which selectivities can be calculated using Eq. (3)..$^{19-21}$

$$
\begin{aligned}
S= & {[\text { ether product }] / \text { alcohol product }] } \\
& \times[\text { water }] /[\text { alcohol solvent }]
\end{aligned}
$$

In this work, we determined rate constants for solvolyses of of 3,4-dimethoxybenzenesulfonyl chloride (DSC) in aqueous binary solvents of acetone, ethanol, methanol, methanol-d and pure water at various temperatures. Transition state variation is also discussed by applying the Grunwald-Winstein equation, extended Grunwald-Winstein equation, Kinetic solvent isotope effects (KSIE) and acti- 
Table 1. Ratc constant $\left(\mathrm{k}^{-1} \mathrm{~s}^{-1}\right)$ for solvolysis of 3,4-Dincthoxybenzencsulfonyl chloride in binary solvent mixture at $25^{\circ} \mathrm{C}^{\mathrm{a}}$

\begin{tabular}{|c|c|c|c|}
\hline \multirow{2}{*}{$\begin{array}{c}\text { solvent } \\
\text { composition }\end{array}$} & \multicolumn{3}{|c|}{ rate constant $\left(k / \mathrm{s}^{-1}\right)$} \\
\hline & methanol-water & ethanol-water & acetone-water \\
\hline 100 & $(1.44 \pm 0.01) \times 10^{-4}$ & $(2.99 \pm 0.28)=10^{-5}$ & - \\
\hline 90 & $(3.34 \pm 0.09\} \times 10^{-1}$ & $(8.72 \pm 0.20)-10^{-5}$ & - \\
\hline 80 & $(5.97 \pm 0.00) \times 10^{-1}$ & $(1.51 \pm 0.01) \times 10^{-4}$ & $(1.63 \pm 0.22\}=10^{-5}$ \\
\hline 70 & $(9.86 \pm 0.04) \times 10^{-1}$ & $(2.28 \pm 0.02): 10^{-4}$ & $(3.61 \pm 0.15\} \times 10^{-5}$ \\
\hline 60 & $(1.51 \pm 0.01\} \times 10^{-\hat{3}}$ & $(3.43 \pm 0.13)=10^{-4}$ & $(8.69 \pm 0.08\} \times 10^{-5}$ \\
\hline 50 & $(2.24 \pm 0.01\} \times 10^{-\hat{3}}$ & $(5.65 \pm 0.06)-10^{-1}$ & $(1.98 \pm 0.02\} \times 10^{-1}$ \\
\hline 40 & $(3.12 \pm 0.01\} \times 10^{-\hat{3}}$ & $(1.03 \pm 0.00) \times 10^{-3}$ & $(4.28 \pm 0.10\} \times 10^{-1}$ \\
\hline 30 & $(4.17 \pm 0.01\} \times 10^{-\hat{3}}$ & $(2.12 \pm 0.00)=10^{-3}$ & $(9.40 \pm 0.00) \times 10^{-1}$ \\
\hline 20 & $(5.07 \pm 0.02) \times 10^{-\hat{3}}$ & $(3.57 \pm 0.01) \times 10^{-3}$ & $(1.78 \pm 0.19\} \times 10^{-3}$ \\
\hline 10 & $(5.33 \pm 0.01\} \times 10^{-\hat{3}}$ & $(4.83 \pm 0.00)-10^{-3}$ & $(3.46 \pm 0.02) \times 10^{-3}$ \\
\hline \multirow[t]{2}{*}{0} & $(5.47 \pm 0.01) \times 10^{-3}$ & $(5.47 \pm 0.01) \times 10^{-3}$ & $(5.47 \pm 0.01\}=10^{-3}$ \\
\hline & TFE-water & 1,4-dioxane-water & acetonitrile-water \\
\hline 97 & $(2.67 \pm 0.00) \times 10^{-6}$ & - & - \\
\hline 80 & $(1.91 \pm 0.01\} \times 10^{-5}$ & - & - \\
\hline 70 & $(4.05 \pm 0.03\} \times 10^{-5}$ & - & - \\
\hline 60 & $(6.86 \pm 0.00) \times 10^{-5}$ & - & - \\
\hline 50 & $(1.27 \pm 0.00) \times 10^{-4}$ & - & - \\
\hline 40 & $(2.47 \pm 0.01) \times 10^{-4}$ & - & - \\
\hline 30 & & $(8.54 \pm 0.02): 10^{-4}$ & $(5.52 \pm 0.02): 10^{-1}$ \\
\hline 20 & & $(1.80 \pm 0.01) \times 10^{-3}$ & $(1.44 \pm 0.00) \times 10^{-3}$ \\
\hline 10 & & $(3.21 \pm 0.02): 10^{-3}$ & $(3.40 \pm 0.03\}) 10^{-3}$ \\
\hline
\end{tabular}

${ }^{2}$ Determined conductimetically in duplicate; errors shoun are average deviations.

vation parameters. In extending this work to the reactions of sulfonyl chlorides, we examined solvolyses of DSC with electron rich substituent as methoxy group and found that these also showed competing reaction channels. ${ }^{22(2)}$<smiles>COc1ccc(S(=O)(=O)Cl)cc1OC</smiles>

3,4-Dimethoxybenzenesulfonyl chloride (DSC)

\section{Results and Discussion}

Kinetic data for solvolyses of DSC at $25.0^{\circ} \mathrm{C}$ are given in Table 1 and KSIE in water, 50\% methanol-water and methanol are in Table 2, and the results at various temperatures are given in Table 3 along with the corresponding activation parameters. Selectivity data were obtained from

Table 2. Kinctic solvent isotope effect of 3,4-dincthoxybenzenesulfonyl chloride at $25^{\circ} \mathrm{C}^{\mathrm{at}}$

\begin{tabular}{cccc}
\hline solvent & $k_{\text {SOI }}$ & $k_{\text {SOD }}$ & KSIE \\
\hline $100 \% \mathrm{MeOH}$ & $1.44 * 10^{-4}$ & $9.96=10^{-5}$ & 1.45 \\
$50 \% \mathrm{MeOH}$ & $2.24=10^{-3}$ & $1.50 \times 10^{-3}$ & 1.50 \\
Water & $5.47 \times 10^{-3}$ & $4.04 \times 10^{-3}$ & 1.35 \\
\hline
\end{tabular}

${ }^{2}$ Determined conduct inetically in duplicate: average deviation $< \pm 3 \%$. product analyses as soon as possible after 10 half-lives of reaction. ${ }^{22}$ Selectivity data for solvolyses of DSC in ethanolwater and methanol-water mixtures at $25.0^{\circ} \mathrm{C}$ are given in Table 4.

As shown in Table 1, the first-order rate constants increase in the order 2,2,2-trifluoroethanol (TFE) -water $<$ acetone-

Table 3. Additional rate constants $\left(k / \mathrm{s}^{-1}\right)$ for solvolyses of 3,4dimethoxybenzenesulfonyl chloride in aqueous alcohol mixtures and the activation parancters calculated using data at $25^{\circ} \mathrm{C}, 35^{\circ} \mathrm{C}$ and $45^{\circ} \mathrm{C}$

\begin{tabular}{lcccc}
\hline Solvent & $\mathrm{T}\left({ }^{\circ} \mathrm{C}\right)$ & $k=10^{4}\left(\mathrm{~s}^{-1}\right)$ & $\begin{array}{c}\Delta \mathrm{H}^{+} \\
\left(\mathrm{kcalmol}^{-1}\right)\end{array}$ & $\begin{array}{c}-\Delta \mathrm{S}^{+} \\
\left(\mathrm{calK}^{-1} \mathrm{~mol}^{-1}\right)\end{array}$ \\
\hline \multirow{3}{*}{$50 \% \mathrm{MeOH}$} & 25 & 22.4 & 14.0 & 23 \\
& 35 & 50.3 & & \\
\hline \multirow{5}{*}{$100 \% \mathrm{MeOH}$} & 35 & 106 & & \\
& 25 & 1.44 & 15.7 & 23 \\
& 45 & 3.62 & & \\
$50 \% \mathrm{EtOH}$ & 35 & 13.8 & & 22 \\
& 45 & 30.5 & & \\
\hline \multirow{5}{*}{$100 \% \mathrm{EtOH}$} & 35 & 0.722 & & \\
& 45 & 1.65 & & \\
\hline $50 \%$ Acetone & 35 & 4.99 & & \\
& 45 & 10.4 & & \\
\hline
\end{tabular}


Table 4. Selectivities $(S)$ for solvolyses of 3,4-dimethoxybenzentesulfonyl chloride in aqueous binary mixtures at $25^{\circ} \mathrm{C}$

\begin{tabular}{cccccc}
\hline \multirow{2}{*}{$\%(\mathrm{v} / \mathrm{v})$} & \multicolumn{2}{c}{ Methanol-water } & & \multicolumn{2}{c}{ Ethano]-water } \\
\cline { 2 - 3 } \cline { 5 - 6 } & {$[$ Ester]/[acid] } & $S$ & & [Ester]/[acid] & $S$ \\
\hline 95 & 11.15 & 1.32 & & 7.47 & 1.28 \\
90 & 8.18 & 2.04 & & 3.98 & 1.43 \\
85 & 6.00 & 2.38 & & 3.00 & 1.71 \\
80 & 4.72 & 2.66 & & 2.41 & 1.95 \\
70 & 3.14 & 3.02 & & 1.65 & 2.30 \\
60 & 2.20 & 3.30 & & 1.23 & 2.65 \\
50 & 1.54 & 3.46 & & 0.80 & 2.59 \\
40 & 1.07 & 3.60 & & 0.49 & 2.39 \\
30 & 0.68 & 3.55 & & 0.22 & 1.68 \\
20 & 0.42 & 3.81 & & 0.10 & 1.32 \\
10 & 0.17 & 3.45 & & 0.04 & 1.12 \\
\hline
\end{tabular}

"Detemined at least in duplicate by IIPLC analyses of two independent solutions: error estimate $\pm 3 \%$.

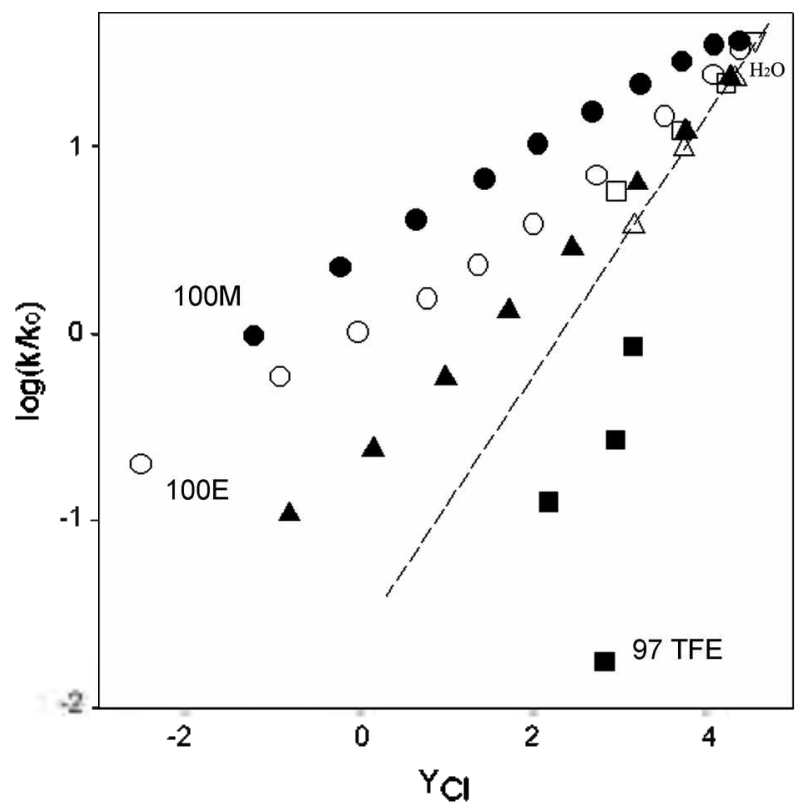

Figure 1. Plot of logarithuns of first-order rate constants for solvolyses of 3,4-dimethoxybenzenesulfonyl chloride against $I_{C I}$ at $25^{\circ} \mathrm{C}: \log \left(k / k_{0}\right)$ 1s. $Y_{\mathrm{Cl}}$ (solvent code: - methanol; $O$, ethanol; $\boldsymbol{\Delta}$, acetone; $\mathbf{\square}$, TFE- $\mathrm{H}_{2} \mathrm{O} ; \square$, 1,4-Dioxane; $\triangle$, acetonitrile; $\nabla$, water).

$\mathrm{H}_{2} \mathrm{O}<$ ethanol- $\mathrm{H}_{2} \mathrm{O}<$ methanol- $\mathrm{H}_{2} \mathrm{O}$. The rate constant also increases as the water content in the mixed solvents increases, indicating that the reaction rate is accelerated by the solvent with higher ionizing power, $Y$ except TFE- $\mathrm{H}_{2} \mathrm{O}$. First-order rate constants increases as the ionizing power $Y$ changes from a lower value to a higher one, i.e., $k_{1}$ increases from $0.0163 \times 10^{-3}$ to $5.47 \times 10^{-3} \mathrm{~s}^{-1}$ as the $Y$ changes from $-0.8(80 \%$ acetone- $20 \%$ water $)$ to $4.57\left(\mathrm{H}_{2} \mathrm{O}\right)^{8}$ for solvolyses of DSC.

The Grunwald-Winstein plots (equation 1) are presented in Figure $I$ using the solvent ionizing power scale $\varepsilon_{\mathrm{Cl}}$ determined from solvolysis of 1-adamantyl chloride. ${ }^{811-14}$ Examination of Figure 1 shows that the plots for the three

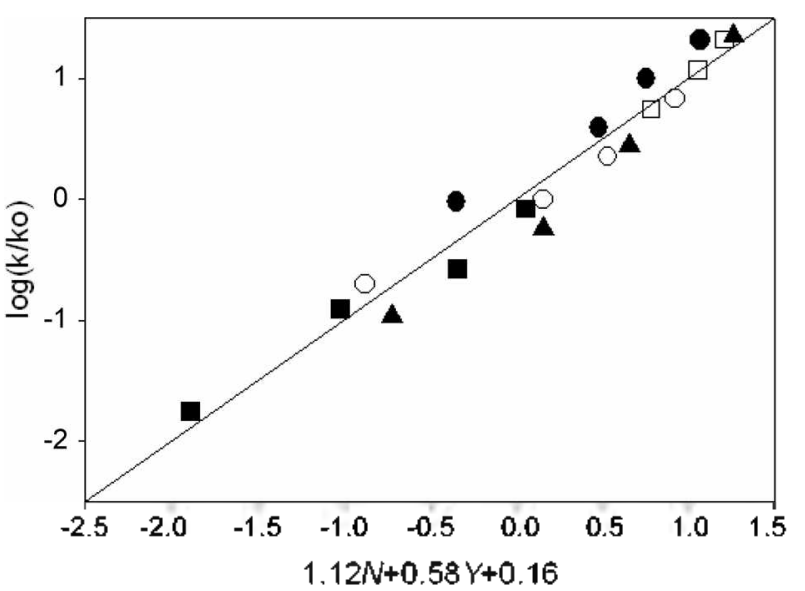

Figure 2. Grunwald-Winstein plot for solvolyses of 3,4dimethoxybenzenesulfonyl chloride at $25^{\circ} \mathrm{C}\left(1.12 N_{\tau}+0.58 \mathrm{I}_{\mathrm{CJ}}\right) \mathrm{r}=$ 0.974 (solvent code: $\boldsymbol{\theta}$, methanol; $\bigcirc$, cthanol; $\boldsymbol{\Delta}$, acetonc; $\boldsymbol{\square}$. TFE- $\mathrm{H}_{2} \mathrm{O} ; \square$, I,4-Dioxane).

aqueous mixtures exhibit dispersions into separate lines. The plots for methanol-water, ethanol-water and acetone-water show a large $m$ value, $m=0.28(\mathrm{r}>0.998), m=0.32(\mathrm{r}>$ $0.998)$ and $m=0.46(\mathrm{r}>0.999)$ and the data points for $97 \%$ TFE solvent mixture show quite large deviations from the correlation of Grunwald-Winstein plots for aqueous alcohol and acetone.

Greater rate constants in $40 \%$ v/v ethanol-water than in $97 \% \mathrm{w} / \mathrm{w}$ trifluoroethanol-water (solvent of approximately equal ionizing power) show the importance of nucleophilic solvent assistance $\left(\mathrm{S}_{\mathrm{N}} 2\right.$ character). Rate ratios in two solvents which have same $\mathrm{I}_{\mathrm{Cl}}$ value, i.e., the same degree of solvent assistance for bond cleavage but different nucleophilicity provides measures of the minimum extent of nucleophilic solvent assistance $\left(e . g .,\left[k_{40 \text { E W }} / k_{97 T \Gamma E}\right]=386\right.$, $\mathrm{EW}=$ ethanol-water) ${ }^{23}$ Thus relatively small $m$ values found $(<0.46)$ and a large $k_{40 \mathrm{E}} / k_{97 \mathrm{TTE}}$ ratio implies that the solvolyses of DSC in the binary mixtures proceed through $\mathrm{S}_{\mathrm{N}}, 2 / \mathrm{S}_{\mathrm{A}} \mathrm{N}^{25}$ pathway channels rather than through an $\mathrm{S}_{\mathrm{N}} \mathrm{I}$ channel.

In order to examine the cause of this dispersion phenomenon, the rate data were correlated using Eq. (2). Inclusion of the nucleophilicity parameter $(N)$ resulted in considerable improvement, indicating that solvent nucleophilicity is important for the current solvolyses of DSC (see Figure 2).

Therefore, such phenomenon can be explained as dispersion effects caused by solvent nucleophilicity. With use of the Grunwald-Winstein Eq. (3), $l$ and $m$ values of 1.12 and 0.58 have been obtained for the solvolyses of DSC (Figure 2). This study has shown that the magnitude of $l$ and $m$ values associated with changing solvent compositions is able to predict the $\mathrm{S}_{\mathrm{N}} 2 / \mathrm{S}_{\mathrm{A}} \mathrm{N}^{25}$ reaction mechanism rather than $S_{k} \cdot 1$.

Quantitative dissection of the rate-rate profiles (Figure 1) into contributions from the competing reaction channels was carried out by a similar method to that reported recently for solvolysis of benzoyl choride, ${ }^{\text {? }}$ and 2,4,6-trimethylbenzenesulfonyl chloride ${ }^{2 t}$ for which two linear regions could be 


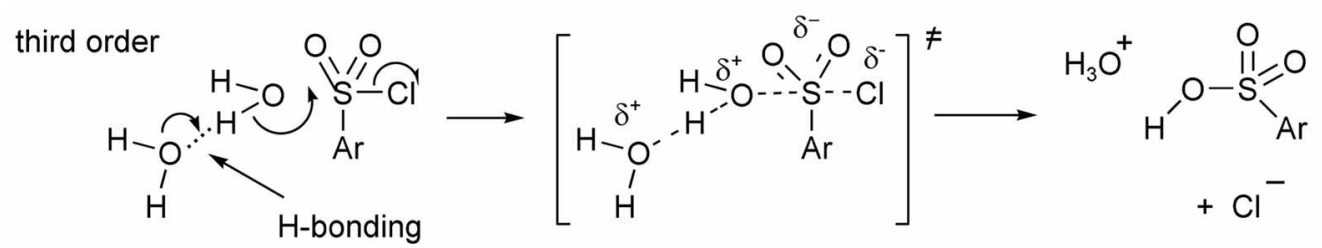

Scheme 1. Mechanism for hydrolysis of DSC - the incehanism favoured in most aqueous alcohols is $\mathrm{S}_{\mathrm{N}} 2$ with general-base catalysis (GBC); the inportance of $\mathrm{GBC}$ is lower for ethanol-water (compared with methanol-water) and for more polar inedia.

seen clearly for each binary mixture. ${ }^{2+}$ The dissected rate constants, calculated for the reaction channel dominant in more polar media, correlated (without significant dispersion) with rate constants for solvolyses of model compound $(p$ methoxybenzoyl chloride). ${ }^{7.26}$ A more approximate procedure was necessary to dissect the rate data for solvolyses of $\mathrm{DSC}$, because the reaction channel dominant in more aqueous media is not so clearly visible (Figure 1 ) and the choice of model compound is less clear-cut. The dashed line (Figure 1) is a least-squares fit to the data points for nine non-alcoholic solvents (i.e. water, $10-20 \%$ acetone-water and dioxane-water, and 10-30\% acetonitrile-water), and which appears on the inspection of Figure 1 to be close to linear. The data points for $10 \%$ ethanol-water also fit this line well: it is the line estimated for the rate-rate profile of the reaction channel dominant in more polar media. When the observed rate constant is greater than predicted from the dashed line the results may be explained through a mechanistic change involving additional contributions from a second reaction channel. ${ }^{2+}$ A line of lower slope could include several data point for ethanol-water mixtures, but not methanol-water mixtures.

Because of ambiguities in the interpretation of Figure 1, independent supporting evidence for the proposal of dual reaction channels was obtained from product selectivities. Maximum $S$ values are observed (Table 4 ) in $60 \%$ ethanolwater mixtures, but there is no clear maximum for methanolwater mixtures.

The point for $97 \% \mathrm{w} / \mathrm{w}$ trifluroethanol-water deviates by a factor of 175 from the hatched correlation line (Figure 1), showing the importance of solvent nucleophilicity in these reactions. ${ }^{27}$ It is now generally accepted that typical solvolyses of sulfonyl chlorides are not $S_{K} 1$ processes. ${ }^{28}$ The large slope (0.69) of the dashed line of the $Y_{\mathrm{Cl}}$ correlation (Figure 1) including data for highly aqueous media is consistent with the proposal of an unusually low degree of charge delocalization from the sulfur atom to the benzene ring in the transition state of an $\mathrm{S}_{\mathrm{K}} \cdot 2$ reaction. ${ }^{24}$ Such a large positive charge in the transition state is likely to lead to an unusual response to changes in solvent ionizing power. ${ }^{2+}$ This dispersion could further complicate interpretation of rate-rate profiles for sulfonyl chlorides (e.g., Figure 1) because, unlike solvolyses of carboxylic acid chlorides, ${ }^{7.26}$ the reaction channel favoured in more polar media may show dispersion. However, $\mathrm{S}_{k} \cdot 2$ reactions of benzyl halides do not show significant reversals in trends of $S$ values, ${ }^{2+29}$ so the $S$ values (Table 4 ) are consistent with a dual reaction channels for solvolyses in ethanol-water mixtures.
The KSIE for reaction of DSC in methanol and water at 25 ${ }^{\circ} \mathrm{C}$ are summarized in Table 2 . If the reaction channel favored in highly aqueous media is an $S_{\mathrm{N}} 2$ process, a different mechanism is required for the second reaction channel favored in the less polar media. ${ }^{24}$ In ethanol- and methanol-water mixtures having a high alcohol content, the slopes $(0.3$, Figure 1$)$ are much smaller than the dashed line $(0.69$, Figure 1). The KSIE (Table 1$)$ of 1.45 for solvolyses of DSC in methanol is greater than that of 1.35 in water (Table 2). Hence, the KSIE obtained from methanol is consistent with a general-base catalysed displacement for the second reaction channel. ${ }^{28+3 \times(5) 30}$ The KSIE (1.34) value in water for solvolysis of $\mathrm{DSC}$ is smaller than that reported for solvolyses of $p$-methoxybenzyl chloride $(1.41)^{s(c)}$ and methanesulfonyl chloride $(>1.51){ }^{25}$ Values in the range from 1.41 to 1.82 for solvolyses of $p$-substituted benzenesulfonyl chlorides ( $p$-OMe to $p$-NOn) at $15^{\circ} \mathrm{C}$ have been correlated with Hammett $\sigma$ values. ${ }^{590}$ Also, the value of 1.35 for DSC is in the range expected for $S_{\mathrm{N}} 2-S_{\mathrm{K}} \mathrm{I}$ processes; ${ }^{31}$ an almost identical value of 1.33 was reported for the hydrolysis of dimethylsulphamoyl chloride ${ }^{28 \mathrm{k})}$ The activation parameters for solvolyses of DSC in aqeuous solvents at $25^{\circ} \mathrm{C}$ are summarized in Table 3 . The negative $\Delta \mathrm{S}^{+}$and large positive $\Delta \mathrm{H}^{+}$support that the solvolytic reaction proceeds through a typical bimolecular reaction. ${ }^{19}$

\section{Experimental Section}

Materials. 3,4-Dimethoxybenzenesulfonyl chloride is a commercial grade (Merck GR-grade $>99 \%$ ). Merck GRgrade $\left(<0.1 \% \mathrm{H}_{2} \mathrm{O}\right)$ acetone, ethanol and methanol were used without further purification. $\mathrm{D}_{2} \mathrm{O}$ and $\mathrm{CH}_{3} \mathrm{OD}$ were from Aldrich $(99.9 \% \mathrm{D})$. Distilled water was redistilled with Buchi Fontavapor 210 and treated using ELGA UHQ PS to obtain specific conductivity of less than $1.0 \times 10^{-6} \mathrm{mhos} / \mathrm{cm}$.

Rate measurments and product selectivies. Rates were measured conductimetrically at least in duplicate as in the previous work. ${ }^{15}$ Activation parameters were determined using the Arrhenius and Eyring equations. The solvolysis products, sulfonic acid and sulfonyl ester, were identified by HPLC analysis as described previously ${ }^{21}$ and the productselectivities, $S$, were calculated from $\mathrm{Eq}$. (3). The $S$ values were calculated from the observed peak area ratios of sulfonic acid and sulfonyl ester, divided by the appropriate response factor. For response calibrations, area ratios from solvolyses of DSC in pure alcohol and in $40 \%$ aceonitrilewater mixtures were used. The eluent was $78 \%$ methanolwater mixture and the flow rate was adjusted to $1 \mathrm{~mL} / \mathrm{min}$. 
The HPLC system was a Hewlett-Packard 1050 Series with a $250 \times 4 \mathrm{~mm}$ Spherisorb ODS reversed column.

\section{References}

1. (a) Barker, J. W; Nathan, W. W. J. Chem. Soc. 1936, 236. (b) Swain, C. G; Langsdorf, W. P. J. Ant. Chent. Soc. 1951, 73, 2813. (c) Rossel, J. B. J. Chem. Soc. 1963, 5183. (d) Yoh, S. D.; Tsuno, Y.; Yukawa, Y. J. Kor. Chent. Soc: 1984, 28, 433. (e) Yoh, S. D. J. Kor. Chem. Soc. 1975, 19, 240.

2. Lee, I.; Rhyu, K. B.; Lee, B. C. J. Kor: Chem. Soc, 1979, 23, 277.

3. (a) Rogne, O. J. Chem. Soc. (B) 1968, 1294. (b) Kim, W. K.; Lee, I. J. Kor Chem. Soc. 1974, J8, 8. (b) Kevill, D. N.; Park, B.-C.; Park, K.-H.; D'Souza, M. J.; Yaakoubd, L.; Milynarski, S. L.; Kyong, J. B. Org. Bionol. Chem. 2006, 4, 1580.

4. (a) Ciuffarin, E.; Senalore, L.; Isola, M. J. Chem. Soc. Perkin Trans. 2 1972, 468. (b) Stangeland, L. J.; Senatore, L.; Ciuffarin, E. J. Chem. Soc. Perkin Trans, 2 1972, 852.

5. (a) Hall, H. K. Jr. J. An. Chem. Soc. 1956, 78, 1450. (b) Robertson, R. E.; Laughton, P. M. Can. J. Chem. 1957, 35, 1319. (c) Rossall, B.; Robertson, R. E. Can. J. Chem. 1971, 49, 1451. (d) Ballistreri, F. P.; Cantona, A.; Maccarone, E.; Tomaselli, G. A.; Tripolone, M. J. Chem. Soc. Perkin Trans. 2 1981, 438.

6. (a) Koo, I. S.; Yang, K.; Kang, K.; Lee, I.; Bentley, T. W. J. Chem. Soc, Perkin Trans, 2 1998, II75. (b) Koo, I. S.; Yang, K.; Kang, K.; Lee, I. Bull. Kor Chent. Sac. 1998, 19, 968. (c) Koo, I. S.; Lee, J. S.; Yang, K.; Kang, K.; Lee, I. Bull. Kor. Chem. Soc. 1999, 20 , 573.

7. Bentley, T. W.; Koo, I. S. J. Chem. Soc. Perkin Trans, 2 1989, 1385.

8. Bentley, T. W.; Carter, G. E. J. Am. Chem. Soc. 1982, 104, 5741.

9. Bentley, T. W.; Harris, H. C.; Koo, I. S. J. Chen. Soc. Perkin Trans. 2 1988, 783.

10. Bentley, T. W. Harris, H. C. J. Chen. Soc. Perkin Trans. 2 1986, 619 .

II. Ko, I. S.; An, S. K.; Yang, K.; Koh, H. J.; Choi, M. H.; Lee, I. Bull. Korean Chem. Soc. 2001, 22, 842,

12. Bentley, T. W.; Bowen, C. T.; Morten, D. H.; Schleyer, P. v. R. $J$. An. Chem. Soc. 1981, 103, 5466.

13. Winstein, S.; Grunwald, E. J. An. Chent. Soc 1948, 70, 846.

14. Bentley, T. W.; Dau-Schmidt, J.-P.; Llewllyn, G.; Mayt, H. J. Org. Chem. 1992, 57, 2387.

15. Winstein, S.; Fainberg, A.; Grunwald, E. J. Am. Chem. Soc. 1957, 79, 4146.

16. Fainberg, A. H.; Winstein, S. J. Am. Chem. Soc. 1957, 79, 1957.
17. Winstein, S.; Gnunwald, E.; Jones, H. W. J. Am, Chem. Soc. 1951 73,2700 .

18. (a) Kevill, D. N.; Ismail, NHJ.;D'Souza, M. J. J. Org. Chem. 1994, 59, 6303. (b) Kevill, D. N.; D'Souza, M. J. J. Chem. Soc. Perkin Trans. 2 1995, 973. (c) Kevill, D. N.; D'Souza, M. J. J. Chem. Soc. Perkin Trans. 2 1997, 257. (d) Kevill, D. N.; Bond, M. W.; D'Souza, M. J. J. Org. Chem. 1997.62, 7869.

19. (a) Harris, J. M.; Clark, D. C.; Becker, A.; Fagan, J. F. J. An. Chem. Soc. 1974, 96, 4478. (b) Harris, J. M.; Becker, A.; Fagan. J. F.; Walden, F. A. J. Am. Chem, Soc. 1974, 96, 4484. (c) Koo, I. S.; Yang, K.; Park, J. K.; Woo, M. Y; Cho, J. M.; Lee, J. P.; Lee, I. Bull. Kor: Chem, Soc. 2005, 26, 124l. (d) Dey, S.; Adhikary, K. K.; Kim, C. K.; Lee, B.-S.; Lee, H. W. Bull. Kor. Chent. Soc 2005 , 26, 776. (e) Oh, H. K.; Ku, M. H.; Lee, H. W. Butl. Kor Chent. Soc. 2005, 26,935.

20. (a) Karton, Y;; Pross, A. J. Chem. Soc. Perkin Trans, 21977, 1860. (b) McLennan, D. J.; Martin, P. L. J. Chem, Soc. Perkin Trans, 2 1982, 1099.

21. (a) Bentley, T. W.; Rvu, Z. H. J. Chen!. Soc. Perkin Trans. 21994 761 . (b) Koo, I. S.; Yang, K.; Kang, K.; Lee, I.; Bentley, T. W. $J$. Chen. Soc. Perkin Trans. 2 1998, 1179.

22. (a) Bentley, T. W.; Harris, H. C. J. Org. Chem. 1988, 53, 724. (b) Bentley, T. W.; Jones, R. O.J. Chem. Soc., Perkin Trans. 2 1993, 2351. (c) Bentley, T. W.; Jones, R. O.; Koo, I. S. J. Chem. Soc. Perkin Trans. 2 1994. 753. (d) Jones. R. O. M. Phil. Thesis; University of Wales: 1991. (e) Koo, I. S.; Bentley, T. W; Lee, I. J. Kor Chem. 1990, 34.304.

23. Bentley, T. W., Llewellyn, G; Ryu, Z. H. J. Org. Chem. 1998, 63, 4654.

24. (a) Koo, I. S.; Kang, D. H.; Bentley, T. W; Lee, I. J. Chem. Soc. Perkin Trofts. 2 1991, 175.

25. Koo, I. S.; Yang. K.; An, S. K.; Lee, C.-K.; Lee, I. Bull. Kor. Chem. Soc. 2000, 21, 1011

26. Bentley, T. W.; Koo, I. S.; Norman, S. J. J. Org. Chem. 1991, 56 , 1604.

27. (a) Schadı, F. L.; Bentley, T. W.; Schleyer, P. v. R. J. Am. Chem Soc. 1976, 98, 7667. (b) Kevil, D. N.; Lin, G. M. L. J. Am. Chem. Soc. $1979,101,3916$.

28. (a) Senatore, L.; Sagramora, L.; Ciuffarin, E. J. Chen! Soc. Perkin Trans. 2 1974, 722. (b) Rogne, O.J. Chem. Soc (B) 1969, 663. (c) Gordon, I. M.; Maskill, H.; Ruasse, M. F. Chem. Soc. Rev. 1989, 18, 123. (d) Kice, J. L. Adv, Phys. Org. Chem. 1980, 17, 156.

29. Aronovitch, H.; Pross, A. J. Chem. Soc. Perkin Trans. 2 1978, 540.

30. Arcoria A.; Ballistreri, F. P.; Spina. E.; Tomaselli. G. A.; Maccarone, E. J. Chent. Soc. Perkin Trans. 2 1988, 1793.

31. Robertson, R. E. Prog. Phys. Org. Chent 1967, 4, 213. 